\title{
Integrating Computer Assisted Instruction in the EFL Classroom of Bangladesh
}

\author{
Naima Afrin
}

\begin{abstract}
In the early 90's education started being affected by the introduction of word processors in schools, colleges and universities. This mainly had to do with written assignments. The development of the Internet brought about a revolution in the teachers' perspective, as the teaching tools offered through the Internet were gradually becoming more reliable. Nowadays, the Internet is gaining immense popularity in foreign language teaching and more educators and learners are embracing it. Undoubtedly, ICT has impacted on the quality and quantity of teaching, learning, and research in traditional and distance education institutions. In concrete terms, ICT can enhance teaching and learning through its dynamic, interactive, and engaging content; and it can provide real opportunities for individualized instruction. Teaching students effectively is a high educational goal throughout the world. In modern world the classroom environment has changed a lot than the previous years for improvement of technology day by day. As there are large number of population in the competitive world, becoming proficient in a new language is a difficult and challenging situation for the learners. ge learner (ESL) need to develop their language through reading, writing, listening and speaking This situation is sometimes frustrating and tendering in the context of Bangladesh if language learning successfully is not possible. English as a second language. Today technological infrastructure of the universities throughout the world has developed a lot. Innovative tools for language learning have been developed for computer assisted instruction. So for developing language skills computer can play an essential part in providing ESL students with valuable language support as they learn a new language spontaneously. Promoted by the educational policy over the past two decades, the technological infrastructure in most universities throughout the world has advanced. Innovative tools of technology for language learning have been developed for computer assisted instruction This article focus on how computer assisted instruction (CAI) can be a supplement al teaching tool for teaching English language learners in tertiary level in Bangladesh. Moreover there is a discussion of the benefits and suggestions for professional development to encourage the professional development in English language development program that have found using CAI with EFL is also analyzed elaborately. In this research project, I reviewed the relevant literature as a means to examine how technology affects second/foreign language education and how it can be used effectively in the secondary EFL (English as a Foreign Language) classroom in Bangladesh. According to the findings of the previous literature, technology integration in second/foreign language education has mostly generated improvement in students' language skills and increased student interests in learning activities. Those types of technology proved to be useful strategies for Bangladesh EFL teachers in informing them how technology can help enhance language learning in the tertiary level.
\end{abstract}

\section{Introduction}

Computer-assisted language learning (CALL) is an approach to teaching and learning foreign language where the computer and computer-based resources such as the Internet are used to present, reinforce and assess material to be learned. It usually includes a substantial interactive element. It also includes the search for and the investigation of applications in language teaching and learning. Except for self-study software, CALL is meant to supplement face-to-face language instruction and not replace it. In recent years, CALL researchers have investigated the advantages of using computers as teaching/ learning tools in improving different language skills. Many studies indicate that CALL provides an innovative and effective alternative for language instructors (Warshauer and Healey, 1998). In addition, many studies indicate that there has been an increase in emphasis on computer technology and itsintegration at all level of education (Stepp-Greany, 2002). Furthermore, computer would allow learners to progress at their own pace and work individually to solve problems, provides immediate feedback, allows learners to know whether their answers are correct or not, and provides them with the correct answers if their answers are not correct.

Computer is being used with high frequency in every field, including the fields of Education and Language Teaching. Thus, ICT and computers exert a high influence on the development of new techniques for teaching and learning languages. The traditionall language classroom, as we all know it, is now being invaded by numerous new approaches and teaching/ learning resources involving the Internet and Computer Assisted Language Learning (CALL), generating significant changes in the roles of both teachers and learners. Although 
the Internet and CALL open a wide range of totally new possibilities for language teachers and learners, the introduction of this new tool into the long-lasting culture of the language classroom is not a simple issue. As Postman (according to AZEVEDO, 2000:2) has pointed out, "it is a mistake to suppose that every technological innovation has only a unilateral effect. Every technology is as much a burden as it is a blessing."

With the introduction of the multimedia computer, the learner and teacher have at their disposal an instrument, which can combine all the advantages of the above-mentioned media in a compact and easily accessible form. The computer may be used as a local machine (stand-alone) or within a network. Computer Assisted Language Learning (CALL) software, CD-ROMs, and office software applications have become commonplace in many teaching/learning environments, and the case studies in Graham Davies' article in this volume illustrate how teachers are making use of them. An inventory of current CALL software, including teacher evaluations of their usefulness/efficiency can be seen at some web sites

\section{Advantages of CALL}

Moreover, there are many more advantages of CALL. Motivation is one such advantage. Motivation can be promoted in students by personalizing information, having animated objects on the screen, and providing practice activities which incorporate challenges, curiosity and providing a context. Adapting to the learning of students is a second advantage of CALL. This means that the student controls the pace of learning and makes choices in what and how to learn, which in turns makes students feel more competent in their learning. The third advantage of CALL is authenticity, the opportunity to interact in one or more of the four language skills by using or producing texts meant for an audience of the target language, not the classroom evaluation. Students feel less stressed and more confident in this language learning situation, in part because surface errors don't matter so much. The fifth advantage of CALL is development of critical thinking skills. It is found that the use of computer technology in classroom generally

improves self-concept, mastery of basic skills and more active processing resulting in higher-order thinking skills and better recall.

\section{Review of related literature}

The review of the literature on Computer-Assisted EFL Instruction revealed that most of the studies in this field were conducted in the Western countries where English is the first language, whereas very few studies were conducted in countries where English is the second or foreign language. The researchers reviewed some of the most related studies to the topic of this study.

Fletcher and Atkinson (1972) carried out one of the earliest studies in which the students of the experimental group received eight to ten minutes of computer-assisted language instruction per day for five months; the remainder of the day was the same for all students. The findings of the study revealed that the performance of most students who received computer-assisted instruction was better than the performance of those who did not.

Cook (1985) determined whether there were significant differences between the growth of writing performance of seventh grade students who received computer-assisted writing instruction and those who did not. He found that the students who received computer-assisted writing showed better performance in writing than those who did not.

Orndorff (1987) implemented a course at Duquesne University in Pennsylvania, which combined the teaching of reading skills with computer aids that provided different kinds of support. He employed two computer programs focusing on critical reading and thinking. The first one was designed to teach students how to analyze a work of literary genre and structure and to be used with a book. The second one allowed teachers to create tutorials which featured different types of question and answer formats, an on-line dictionary, screen manipulations.

Avent and Joseph Harmon (1994) investigated the language learning achievement differences between students using computer- assisted language learning courseware and students using the traditional language laboratory. The findings of the study revealed that the mean scores were significantly higher for computer taught items than for non-computer taught ones.

Chen (1996) studied the differences between male and female Taiwanese students using the same software and receiving the same type of feedback in a Business English class. The findings

showed that computer application improved the students' htiugfv iting ability in punctuation, grammar and spelling.

Pigg (1996) investigated the effect of the computer-assisted language instruction program Paragraph Builder on fifth grade students' topic sentence identification. The results of the posttest showed that the program significantly increased the mean score of the posttest. The results also showed that the students who worked with computer enjoyed learning about topic sentences by using the program. 
Cantos-Gomez (1997) carried out a study to investigate the use of computer-assisted language learning activities in English and their effect on the students' motivations to learn. She found that the students in the experimental group, who used computer, showed more motivations to learn English than those in the control group.

Machado (1997) investigated the effect of computer-based technology on the language acquisition rates of sixth, seventh and eighth grade second language students in writing and

speaking. The study revealed that the experimental group showed a faster rate of second language acquisition than that of the control group students.

Blankenship (1999) compared between computer-assisted instruction and the lecture-based instruction of college-level composition courses. The findings of the study showed that the performance of the students who received computer-assisted instruction was better than those who did not.

Tozcu (1998) investigated the impact of teaching sight vocabulary with computer-frequent word recognition and reading comprehension. He found that the experimental group presented significantly greater gains than the control group. Campion (1999) investigated the effect of CALL on learning and transfer of vocabulary in primary stage pupils. The researcher tackled two issues: motivation and the role of educational technology in learning and transferring of passive

vocabulary into the active. The findings of the study showed that the pupils who learned via CALL improved their results in both types namely in active vocabulary.

AbuSeileek (2007) investigated the effectiveness of twomediated techniques - cooperative and collective learning - designed for teaching and learning oral skills, listening and speaking. He also investigated students' attitudes toward using a CALL approach and techniques for teaching oral skills. The findings of the study showed that the cooperative computermediated technique is a functional method for learning and teaching oral skills. The survey conducted in the study also

\section{Prerequisites for successful integration of ICT}

The vast potential of ICT should not blind us to the fact that quality, not quantity is required here, as in other areas of education. Studies have shown that technology is most successfully developed in the language classroom when:

- there is a real reason for using it;

- alternative activities are to hand, if problems arise;

- training and support is given to learners;

- the use of technology is integrated and ongoing;

- the activities engaged in are stimulating and worthwhile to the learners;

- communication is taking place between learners;

- learners are asked to use language in meaningful ways.

\section{Research Questions}

The study attempts to answer the following questions:

Q1: What are the opinions of ESL/EFL students and teachers at tertiary level regarding the use

of CALL in a language classroom?

Q2: What are the challenges that ESL/EFL students and teachers at tertiary level face while using Computer assisted tools in a language classroom?

Q3: What are the possible strategies to successfully overcome the challenges that ESL/EFL students and teachers face while using CALL pedagogical tools in a language classroom?

\section{Setting and Participants}

The setting of this investigation was English Foundation Course in three private universities in Bangladesh . 12 English Language Faculties and 52 ESL/EFL students participated who were selected randomly from semester 1 and 2 . The students, ranging in age between 18 to 23, were both male and female.

\section{Instrument}

A questionnaire with close and open-ended questions was administered with students asking them to indicate on a four-point Likert scale their degree of agreement on 18 statements . 


\section{Perceptions of the learners:}

The questionnaire comprised both structured (closed) and unstructured (open ended) questions. Students were requested to give their honest views in a 4--Likert scale. The scale was comprised as follows; Strongly Agree, Agree, Disagree, and Strongly Disagree. Scores on each question ranges from 1 to 4, with lower values indicating more negative attitudes. The following result shows some perceptions of the learners:

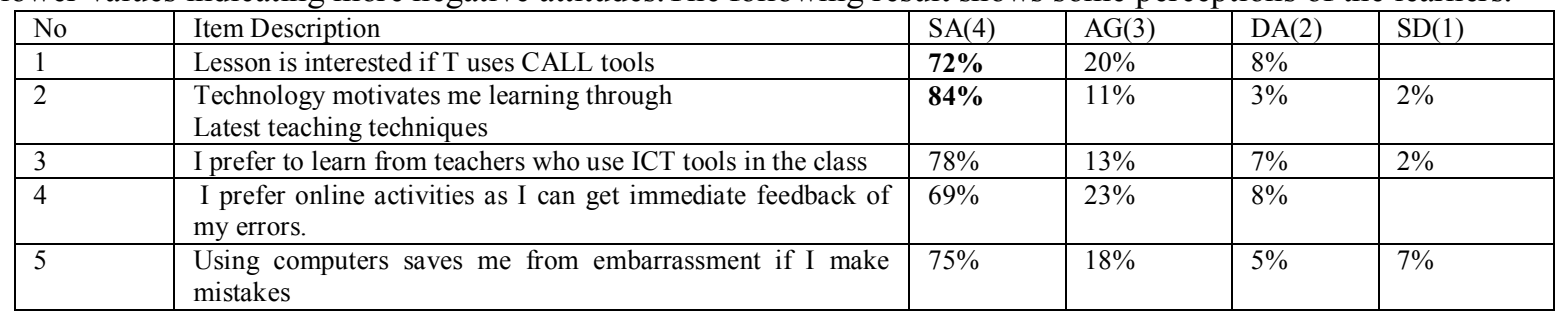

Here the students perceive that ICT "can help students take ownership of their learning, make them autonomous and confident in their learning, enable introvert students interact freely, acquire valuable study and time management skills with better intrinsic impetus for learning and

teachers can have a more student-centered form of learning". These perceptions have also been

replicated in the questionnaire data. Out of total 52 students, $72 \%$ students strongly agreed, $20 \%$ agreed and $8 \%$ disagreed that "the lesson is more interesting if teacher uses electronic tools" and $78 \%$ \& $13 \%$ strongly agreed and agreed that "they prefer learning from a teacher who uses various e-tools while teaching". This shows learners' high demand to learn from latest digital devices adding extra pressure and responsibility on language educators to reengineer their selection and use of teaching materials. Participants favored combination of instructor-led traditional learning and computer-aided learning.Here the result also shows that only $8 \%-2 \%$ students show their reluctance in using ICT tools in language learning. They comments "CALL makes difficult to understand the lesson as we are not strong enough in the technology and advanced vocabulary.However they acknowledged that ICT tools make the learning environment easy and enjoyable place to learn language.

\section{Procedure with the faculties:}

An online interview was conducted with teachers who were asked to answer seven questions related to their opinion on CALL, challenges they face and strategies to overcome them. It was semi-structured with the following seven open-ended questions:

1. What do you think about the use of computers in the classroom?

2. What do you think are the advantages of using computers in the classroom?

3. What do you think are the disadvantages of using computers in the classroom?

4. Do you think CALL can contribute to students' language development? If yes, how? If no, why not?

5. What factors do you think influence your use of CALL? How much?

6. What do you think about the future of CALL in terms of the teaching of EFL?

7. Do you have any suggestions to make in relation to CALL practice?

\section{Procedure}

All the faculties were approached via e-mail, text messages and phone calls. The purpose of study was explained to them and they were informed that their participation was voluntary. The participants responded via e-mails.

\section{Data Analysis}

The percentage of each response was obtained using excel sheet and the qualitative data were categorized into main themes to find out opinions, challenges and strategies of using CALL tools.

\section{Findings and Discussion}

The study found a number of opinions, challenges and strategies.

Of the twelve teachers who participated in the study, eleven teachers indicated that they use the computer in the classroom and use it mainly for conducting multimedia classes, listening and other activities. Among the eleven teachers, eight teachers indicated that they use the computer less than 5 hours a day and three teachers indicated that they use the computer more than 5 hours a day. It was also found that ten teachers use the computer very often (more than three times a week) while one teacher uses the computer sometimes (once to twice a month) for language instruction in the classroom.

Regarding teachers' self-rated computer skills, ten teachers indicated that their computer skills are fair or good while two teachers confessed that their computer skills are poor. In the question of CALL applications 
they mainly use in the classroom, the teachers showed their preference to CD-ROMs and the Internet. During the past two years, eight teachers did not participate in any in-service training courses while three teachers took in-service teacher training courses to learn how to use computers for teaching purposes. The three teachers who took training courses reported that the courses have been very helpful for technology integration in their classrooms. The eight non-participants in training courses reported that they did not take them because of limited time or no interest in training courses.

\section{Data from the interviews with Teachers}

\section{Using computers in the classroom}

Of the twelve teachers, eleven teachers considered using the computer as vital and necessary in an era of modern technology. It appeared that they naturally accepted the use of technology as an undeniable part of instruction.

"It is very important to use computers in the classroom. Using technologies in the classroom has many benefits to teachers and students alike. It is helpful for increasing students' motivation with effective audiovisual materials."

Three teachers described the effectiveness of using computers and referred to changes in the way of teaching and presentation methods. For example:

"When I teach with the help of computers, I don't need to bring a cassette player with me from classroom to classroom and very easy to deliver."

"It saves time for teachers because we don't need to write on the blackboard again and again. By using computers, we can provide students interesting lessons full of real pictures, images, animations and video clips.”

Some teachers argued that they might be preoccupied with classroom management over learner behaviour while using computers in the classroom. Also, they stated that students' motivation and attention could be distracted by fatigue of students' eyes and necks and environmental reasons such as the fixed classroom layout and poor computer facilities at university.

When they were asked about disadvantages of computer-assisted instruction, two teachers mentioned a lack of time and stated that they need more time and efforts to create or find teaching materials. For example:

"It takes much time for preparing teaching materials and activities. I need to surf the Web, find appropriate materials and modify them according to the levels of my students. Sometimes I need 2-3 hours to create materials for a 20 -minute presentation in class."

"I feel problem delivering lecture with CALL because in my lecture I explain lots of criticism spontaneously and teaching with computer interrupts my spontaneity."

\section{Teachers' perceptions of and attitudes toward CALL}

The results of the study indicate that the teachers' perceptions of and attitudes toward CALL are generally positive. By the teachers' responses to the questionnaire and interviews, We can come to the result that all teachers consider new learning contexts created by the use of computers as essential and expected environments for the ICT-based global society. They tend to believe that the use of computers adds value to their teaching and CALL is an effective way for improving the quality of their teaching because CALL can provide both teachers and students with useful information and resources, various modes of presentation and authentic contexts in their teacher and learning. The eleven teachers who had positive perspectives on the effectiveness of CALL tried to use computers and computer-based materials for language instruction although they faced many difficulties and barriers in their own contexts. It come into views that CALL is accepted among the teachers because they are aware of the benefits of using computers in foreign language learning and teaching.

However, the teachers also believe that using computers in the classroom cannot completely provide better quality teaching but they think that quality education also depends on the teachers' quality and also their positive attitude and effort to implement new technologies and teaching materials to class .By these efforts they guarantee effective language teaching.

The teachers in the study agree that computer technologies are helpful for enhancing students' language learning. They prefer to use a Word Processor, PowerPoint, the Internet and CD-ROMs in the classroom as teaching tools. Among the tools, they consider the CD-ROMs \& PowerPoint as the most effective teaching aids in their teaching in the classroom. In spite of limited computer facilities at universities, they tend to believe that beside that the Internet can be used in various ways and provide students with opportunities to engage in real and authentic learning They also agree that teachers and students can communicate with native speakers of English with computer-mediated communication (CMC) tools over the Internet. Such experiences can help language learners develop their communicative competence through interaction with other people, practice the language beyond the classroom and understand cultural diversities. 


\section{Some factors for CALL implementation:}

Teachers' opinion about barriers in CALL implementation: According to Teacher's opinion there are a number of difficulties in CALL implementation. Those are:

- Limited time

- Insufficient computer

- Inflexibility of curriculm and textbook

- Lack of administrative support .

- Teacher's limited skills and knowledge about CALL

The results of the study also indicate that social pressure can have a negative or positive impact on teachers' decision about the use of CALL, material preparation, activity design, class management and lesson planning. While four teachers have negative feelings about social pressure and expectations from others, three teachers assert that they should do their best to meet the demands from the university and society as an innovative teacher. They add that the pressure makes teachers be frustrated and discouraged at first, but eventually it is a driving force or a facilitating factor to improve their teaching skills and knowledge. They emphasize that teachers should participate in teacher training actively to improve their computer skills and build up self-confidence. At this point, it seems certain that teachers' positive attitudes toward social demands and enthusiasm for professional development significantly influence their willingness to utilize CALL in the classroom.

\section{Suggestions for improving CALL practice:}

For the implementation of CALL in the classroom, the teachers in the study suggest:

- Well-equipped computer facilities, language labs and appropriate technical and administrative support should be provided.

- Reconsidering current textbooks and national curriculum for CALL practice.

- Importance of the improvement of the CD-ROMs they use frequently in the classroom.

- Training for one-to-one or small group tutoring so that teachers can practice computer literacy skills and can be competent in CALL in their own contexts

- supportive and collaborative relationships between fellow teachers with the same needs are formed in familiar and friendly learning environments.

As computer technology plays a more and more significant role in education, it is necessary for language teachers to examine how to integrate CALL into the EFL classroom of Bangladesh. The findings of the study reported in this article indicate that the teachers of EFL have positive attitudes toward the use of computers in general and recognize the benefits of using CALL in the language classroom. They think that the future of CALL is bright since the computer has become a basic tool for learning and teaching. While agreeing that CALL can provide students with highly motivated learning environments and opportunities to engage in meaningful and authentic learning, they point out that the Internet serves as a useful educational tool for motivating students, providing a large amount of information, teaching resources and materials and a place for experiencing different cultures and communicating with other people in the target language.

There are several theoretical and practical implications for effective CALL implementation in EFL contexts. First, it is suggested that teachers should be provided with well-equipped computer facilities and technical and administrative support. Even though teachers have positive attitudes toward CALL, limited availability of computer facilities can make them feel discouraged to use CALL. If sufficient computer facilities assisted by technical support are available at schools, teachers would be inspired to use CALL actively in their classrooms. Second, in order to reduce the inconsistency between teaching with technology and existing curricula, educators who develop educational software and language programs should make links between textbooks and curricula in line with CALL pedagogy. Third, educators should develop level-differentiated CALL software programs to respond to students' needs, interests, backgrounds and learning styles. The programs must be upgraded regularly to reflect feedback from teachers and students. Fourth, university -based small group teacher training is recommended because it can provide individual teachers with sound pedagogy and practical skills for CALL. It can be based on one-to-one or small group tutoring in order to give teachers enough opportunities to practice necessary computer skills and teaching methods applicable to their classrooms. Through this kind of training, teachers can acquire computer literacy and integration skills, develop positive attitudes toward CALL and build up supportive and collaborative relationships with colleagues at their schools. Fifth, CALL-related organizations, communities or ESL/EFL Websites for local teachers can be helpful for sharing valuable teaching experiences with CALL, creative ideas, useful information and resources with others. 
Through on-line discussions or off-line meetings, teachers can discuss practical issues of CALL with other teachers. Finally, teachers need to have positive attitudes toward the changes of society and technology use. Teachers' personal beliefs of the advantages of CALL are helpful for improving their self-confidence and practical teaching skills. Therefore, it is important for teachers to make personal efforts to set up learning goals, prepare authentic materials suitable for the level of students and integrate them into the classroom.

\section{References}

[1]. Andréa Machado de Almeida Mattos Universidade Federal de Minas Gerais "Virtual Classrooms in Brazil: teachers' difficulties and anxieties towards technology in language learning"

[2]. Anthony Fitzpatrick (Germany) \& Lev Gordon "Information and Communication technologies in the teaching and learning of foreign languages: State-of-the-art, needs and perspectives".

[3]. Muhammad Tanveer Majan College (Oman) "Integrating E-learning in Classroom-based Language Teaching: Perceptions, Challenges and Strategies"

[4]. S. S.C. Young National Tsing Hua University, Taiwan "Integrating ICT into second language education in a vocational high school” Journal of Computer Assisted Learning (2003) 19, 447-461.

[5]. Chan Nim Park \& Jeong-Bae Son “ Implementing Computer-Assisted Language Learning in the EFL Classroom: Teachers' Perceptions and Perspectives" International Journal of Pedagogies and Learning, 5(2). November 2009.

[6]. Nasser Saleh Al-Mansour *, Ra'ed Abdulgader Al-Shorman "The effect of computer-assisted instruction on Saudi University students' learning of English” Journal of King Saud University - Languages and Translation (2011) xxx, xxx-xxx. 